\title{
Pathology of Animal Transmissible Spongiform Encephalopathies (TSEs)
}

\author{
John Spiropoulos, Marion M. Simmons \\ Animal and Plant Health Agency (APHA), Weybridge, UK
}

\begin{abstract}
Pathology is the study of the structural and functional changes produced by diseases or - more specifically - the lesions they cause. To achieve this pathologists employ various approaches. These include description of lesions that are visible to the naked eye which are the subject of anatomic pathology and changes at the cellular level that are visible under the microscope, the subject of histopathology. Changes at the molecular level which are identified by probes that target specific molecules mainly proteins that are detected using immunohistochemistry (IHC). As transmissible spongiform encephalopathies (TSEs) do not cause visible lesions anatomic pathology is not applicable to their study. For decades the application of histopathology to detect vacuoles or plaques was the only means of confirming TSE disease. The subsequent discovery of the cellular prion protein $\left(\mathrm{PrP}^{\mathrm{C}}\right)$ and its pathogenic isoform, $\mathrm{PrPSc}$, which is a ubiquitous marker of TSEs, led to the production of anti-PrP antibodies, and enabled the development of $\mathrm{PrP}^{\mathrm{Sc}}$ detection techniques such as immunohistochemistry, Histoblot and PETblot that have evolved in parallel with similar biochemical methods such as Western blot and ELISA. These methods offer greater sensitivity than histopathology in TSE diagnosis and crucially they can be applied to analyze various phenotypic aspects of single TSE sources increasing the amount of data and offering higher discriminatory power. The above principles are applied to diagnose and define TSE phenotypes which form the basis of strain characterisation.
\end{abstract}

Key words: animal, TSEs, pathology, prion, $\operatorname{PrP}$

\section{Techniques and Applications of Pathology}

Probably the oldest simplest definition of pathology is 'the study of disease'. More specifically the aim of pathology is to describe the lesions that are caused by diseases. Some lesions can be large enough to be observed without any specialist equipment. Such lesions are designated as gross lesions and they are the subject of anatomic pathology.

The introduction of the microscope revolutionized pathology as it gave an insight of tissue changes that occur within gross lesions at the cellular level. Furthermore, it was made evident very quickly that cellular changes are not always confined within the boundaries of gross lesions but they can also be observed in tissues that look normal macroscopically. This increases our ability to detect disease sooner and to identify more accurately the extent of the disease in an animal. The study of the microscopic lesions is the subject of histopathology.

The development of molecular techniques has given pathologists the opportunity to study disease-associated changes at the molecular level. Molecular changes can be detected even in the absence of gross or histological lesions and they are considered to be the first indicators of disease. Therefore, detection of molecular changes increases further

Received: 3 November 2016; Accepted: 24 November 2016; Published online: 8 February 2017

Corresponding author: John Spiropoulos, Pathology Department, Animal and Plant Health Agency (APHA), Woodham Lane, New

Haw, Addlestone, Surrey KT15 3NB, UK (john.spiropoulos@apha.gsi.gov.uk)

The contents of this article reflect solely the view of the author(s).

Conflict of interest statement: The authors had no conflicts of interest to declare in this article.

This paper was presented at the Animal Prion Diseases Workshop "Updated Diagnosis and Epidemiology of Animal Prion Diseases for Food Safety and Security" supported by the OECD Co-operative Research Programme. (See "Food Safety" Vol.4 (2016), No.4, 103-4.) Abbreviations: BSE: bovine spongiform encephalopathy; CWD: classical scrapie, chronic wasting disease; EM: Electron microscopy; FACS: fluorescent assorted cell sorting; IHC: immunohistochemistry; LP: lesion profiles; LRS: lymphoreticular system; PCR: polymerase chain reaction; PRNP: PrP gene; $\operatorname{PrP}^{\mathrm{C}}$ : cellular prion protein; TME: transmissible mink encephalopathy; TSEs: transmissible spongiform encephalopathies 
our ability to detect disease at the very early stages. The commonest molecular pathology technique is immunohistochemistry (IHC) where a specific protein can be detected in tissue sections using antibodies that have been raised against it. Immunocytochemistry is based on the same principle but it is applied on slide smears prepared from cell suspensions. Specific RNA or DNA molecules are detectable using in situ hybridization or in situ polymerase chain reaction (PCR).

Electron microscopy (EM) has increased the magnification and resolution of the pathology images and although EM is not used routinely for diagnostic purposes because of the expertise required and the costs involved it remains a very powerful research tool particularly when it is combined with IHC.

More recently technologies such as fluorescent assorted cell sorting (FACS), confocal microscopy, laser capture microscopy and microarrays are applied mainly in research pathology laboratories but some of these techniques are expected to revolutionise diagnostic approaches.

Currently immunohistochemistry, immunocytochemistry and to a lesser extent in situ hybridization using either light or fluorescent microscopy are the most widely used molecular pathology applications, particularly for diagnostic $\operatorname{purposes}^{1,2)}$.

\section{Basic Biology of Transmissible Spongiform Encephalopathies (TSEs)}

TSEs are neurodegenerative, incurable and fatal diseases of the nervous system. TSEs do not cause gross lesions but they are characterised by microscopic vacuolation in the brain which gives a spongiform appearance, giving rise to the term spongiform encephalopathies. Another hallmark feature of TSEs, although not always present, is the formation of amyloid plaques in the central nervous system (CNS) ${ }^{3)}$.

Originally it was believed that the causative agent of TSEs was a virus. However, no viral particles were ever detected and it was shown that infectious tissues would retain infectivity after exposure to inactivation treatments that would kill conventional viruses. Meanwhile, experimental evidence accumulated supporting a theory, first suggested in 1967, that the major or single component of the infectious agent could be a cell membrane bound protein ${ }^{4,5}$. According to this theory, known as the prion theory, a naturally occurring protein, prion protein or PrP, can under certain circumstances alter its configuration from its normal cellular structure, $\mathrm{PrP}^{\mathrm{C}}$, and adopt a pathogenic tertiary conformation, designated $\mathrm{PrP}^{\mathrm{Sc}}(\mathrm{C}$ denotes the cellular form and $\mathrm{Sc}$ denotes pathogenic conformer) ${ }^{6,7)}$.

$\mathrm{PrP}^{\mathrm{C}}$ has a mainly a helical composition ${ }^{8,9)}$ whilst $\mathrm{PrP}^{\mathrm{Sc}}$ has a mainly beta sheet structure ${ }^{10,11)}$. It is believed that the beta sheet composition can adopt numerous distinct tertiary conformations which account for the different strains of the agent $^{12,13)}$. This has been a very significant development as it provided an explanation for the existence of different 'strains', a major point of debate for the researchers who were advocating that an independent genome is a prerequisite for an organism that presents as multiple strains. Due to its enriched beta sheet structure compared to $\mathrm{PrP}^{\mathrm{C}}, \mathrm{PrPSc}^{\mathrm{Sc}}$ is more resistant in vitro to digestion by proteinase $\mathrm{K}$ and also to cellular digestion ${ }^{14,15)}$, a feature which can be exploited by diagnostic tests ${ }^{16)}$.

The presence of $\mathrm{PrP}^{\mathrm{Sc}}$ in the brain, either by transport after peripheral exposure (bovine spongiform encephalopathy (BSE), classical scrapie, chronic wasting disease (CWD), transmissible mink encephalopathy (TME)) or by de novo stochastic generation (most likely atypical scrapie, $\mathrm{H}$ - and L- type BSE), acts as a seed that provides a template of self-propagation by converting endogenous $\mathrm{PrP}^{\mathrm{C}}$ to $\mathrm{PrP}^{\mathrm{Sc}}$. Therefore, unlike other pathogens, which retain their own genome when they invade and infect different hosts, $\mathrm{PrP}^{\mathrm{Sc}}$ always adopts the sequence of the host $\operatorname{PrP}^{C}{ }^{17)}$. The pathogenicity is determined by the different tertiary conformations $\mathrm{PrP}^{\mathrm{Sc}}$ can adopt ${ }^{18)}$.

\section{TSE Diagnosis}

The primary testing methods now used routinely for large scale disease screening rely on the detection of $\mathrm{PrPSc}^{\mathrm{Sc}}$. However, histopathology is still used for the confirmation of TSEs in surveillance and research projects ${ }^{19-21)}$. Using histopathology, identification of vacuoles in the grey matter of brain or spinal cord sections stained with haematoxylin and eosin was the first diagnostic criterion of TSEs ${ }^{3,22)}$. Identification of amyloid plaques in similar sections is another diagnostic hallmark of TSEs but unlike vacuolation which is considered to be ubiquitous the presence of plaques is not ${ }^{3)}$. Histopathology is one of the few approaches that is not reliant on an antibody raised against $\operatorname{PrP}$.

The discovery of $\mathrm{PrP}^{\mathrm{C}}$ and $\mathrm{PrP}^{\mathrm{Sc}}$ and the ability to raise antibodies that can bind to them gave rise to the development of reliable IHC techniques that identify $\mathrm{PrP}^{\mathrm{Sc} 23-25)}$. As $\mathrm{PrP}^{\mathrm{C}}$ and $\mathrm{PrPSc}^{\mathrm{Sc}}$ are both present in tissue sections and antibodies raised specifically against $\mathrm{PrP}^{\mathrm{Sc}}$ are not widely available, specific detection of $\mathrm{PrP}^{\mathrm{Sc}}$ is achieved by carefully adjusting the titre of the anti-PrP antibody and the exposure time so that only $\mathrm{PrP}^{\mathrm{Sc}}$ is identified. Specific pretreatment is required to enhance the detection of $\mathrm{PrP}^{\mathrm{Sc}}$ by facilitating antigen retrieval $^{26,27)}$ but the exact mode of action is unknown. This is in contrast to other methods such as Western blot or ELISA 
where the sample is treated with a protease for a specified time during which the protease sensitive $\mathrm{PrP}^{\mathrm{C}}$ is destroyed whilst the relatively protease resistant $\mathrm{PrP}^{\mathrm{Sc}}$ is retained and subsequently detected by the anti-PrP antibody ${ }^{16}$. Tissue sections can also be treated with protease, but it is believed that the agent only affects the free surface of the section and it may help in general antigen retrieval rather than specific elimination of $\operatorname{PrP}^{\mathrm{C}}$. Application of protease for extended periods, to reach the deeper layers of the section, usually digests most or the whole of the section with detrimental effects on $\mathrm{PrP}^{\mathrm{Sc}}$ detection and tissue morphology. It has also been reported that streptomycin may be used to amplify immunohistochemical detection of $\mathrm{PrP}^{\mathrm{Sc}}{ }^{28)}$. The majority of laboratories that apply immunohistochemistry to detect $\mathrm{PrP}^{\mathrm{Sc}}$ currently use no protease or streptomycin pretreatment.

\section{TSE Disease and Strain Characterisation}

Because prions do not have their own independent genome, methods such as PCR or other techniques that are used widely in strain typing of bacteria, viruses or other organisms cannot be applied to TSEs. However, different TSE strains, can be identified by studying the disease phenotype in a specified host ${ }^{29,30}$. Phenotype is the composite metabolic, physiological and physical characteristics, both normal and pathological, exhibited by a host as a result of its interaction with the environment inside and outside the organism. Disease phenotype includes all the pathological characteristics caused by a disease in a host. By definition, the phenotype is host specific and includes a very large number of parameters which may evolve over time as new techniques are applied. For practical purposes in TSEs the parameters that are currently considered to define phenotype are incubation period, clinical signs, and quantitative aspects of vacuolation which give rise to lesion profiles, IHC deposition patterns and Western blot characteristics ${ }^{31-33)}$. For the purposes of this review different phenotypes in the original host are considered as different TSE strains ie BSE, H- type BSE and L- type BSE in cattle, and classical and atypical scrapie in sheep. However, after experimental transmission of a TSE to wild type or transgenic rodents a single or multiple phenotypes may emerge in a single mouse line, leading to the laboratory definition of a strain. According to this definition, classical scrapie includes several strains as various distinct phenotypes can be identified in mice ${ }^{33-35)}$. In contrast every time a source of atypical scrapie has been bioassayed in mice a single phenotype has been detected suggesting that atypical scrapie is attributed to a single strain ${ }^{36,37)}$. It must be emphasized that, particularly in rodents, the phenotypes are not simply host specific but mouse line specific ${ }^{30,33,38)}$.
This means that phenotypes between different mouse lines are not directly comparable even within wild type mice due to polymorphisms in the murine PrP and other genetic factors ${ }^{34,39-41}$. TSE strain characterisation using mouse bioassays is considered part of the phenotype of a TSE but this complete phenotype is only available in a minority of cases and it is not usually included in the phenotype of every TSE case identified in the field.

Classification of phenotypes requires more detailed data than simple disease diagnosis. Therefore more elaborate pathology interpretation approaches have been developed.

For histopathology the density and distribution of vacuolation in the brain can be assessed semi-quantitatively at specified neuroanatomical areas and plotted to produce graphs, termed lesion profiles (LP) ${ }^{42,43}$. Although LP approaches have been used for disease classification in the original hosts they are very elaborate and cannot be applied routinely, not least because for practical and financial reasons the only brain areas that are regularly sampled for surveillance purposes are brain stem and cerebellum. LP are used widely in experimental studies, particularly in rodents, and are considered disease/strain specific ${ }^{42,44)}$. However, because lesion profiles were originally optimised to detect a specific mouse adapted classical scrapie strain (ME7) in CBA or C57BL/6 mice exceptions can occur ${ }^{45}$ ) as the methodology has been used relatively unchanged since it was developed ${ }^{42)}$ to every other TSE strain in any mouse line. This method is semi- quantitative and it requires that the profiles are applied to animals dying during the clinical phase of the disease. At least five clinically positive animals should contribute to a lesion profile for it to be considered robust, although this is not always possible if attack rates are $\operatorname{low}^{33,46)}$.

The application of IHC revealed a variety of different $\mathrm{PrP}^{\mathrm{Sc}}$ deposits classified morphologically as intraneuronal, intraglial, granular, punctate, coalescing, plaques etc ${ }^{24,38,47)}$. It was observed that each TSE strain/host combination produces a unique IHC signature. These signatures can be assessed semi-quantitatively at predetermined specific neuroanatomical areas to produce graphs similar to lesion profiles ${ }^{48,49}$. As these IHC profiles are semi quantitative approaches the same restrictions regarding the clinical status of the animals and the number of animals that have been mentioned for the LP apply. Alternatively the distribution of the different $\mathrm{PrP}^{\mathrm{Sc}}$ types can be used to produce high definition neuroanatomical maps that are strain specific ${ }^{33,50,51)}$. The later approach is very powerful, as it does not require semiquantitative assessment in predetermined brain areas. As a result it can be applied successfully to single animals from the preclinical stages to allow TSE characterisation when adequate hallmarks of the specific TSE are recognised. It can 
also be used to identify TSE strain coinfection provided that the signature of each TSE is expressed to an extent that can be identified by the reader ${ }^{46)}$.

Histoblot is a technique that allows application of a protease to eliminate $\mathrm{PrP}^{\mathrm{C}}$ and preserve $\mathrm{PrP}^{\mathrm{Sc}}$ in tissue sections. Frozen tissue sections are mounted on nitrocellulose membrane and are subsequently treated and developed in the same way as a Western blot ${ }^{52-54)}$. This method can also be applied to paraffin embedded tissue sections (PET-blot) ${ }^{55,56)}$. Pathology laboratories usually prefer PET-blots as they archive tissues in paraffin blocks. Although histo- or PET- blots are useful in specific applications, the resolution is significantly reduced compared to IHC as it is not possible to differentiate different $\mathrm{PrP}^{\mathrm{Sc}}$ types, with the possible exception of plaques, and therefore only the extent of distribution of $\mathrm{PrP}^{\mathrm{Sc}}$ in the brain can be determined ${ }^{38)}$. Histo- or PET- blot is also applied to individual mice, but because it has a lower resolution than IHC, neither histo- or PET- blot can be used to identify coinfection in single animals.

\section{Application of Disease Phenotype to Define TSEs and TSE Strains in Small Ruminants}

\section{Classical Scrapie}

Classical scrapie is considered to be the archetypical TSE and is known since 1732 ${ }^{57,58)}$. The sheep PrP gene (PRNP) is highly polymorphic, and some codons have been identified which can susceptibility to scrapie and can also affect disease phenotype. An association between incubation period and PRNP genotype has been reported ${ }^{59,60)}$, and LP also appear to be $P R N P$ dependent ${ }^{43)}$. It has been suggested that in sheep it may be possible to identify different scrapie strains in the original host using a single phenotypic characteristic, $\mathrm{IHC}^{47}$ ). However, that study involved experimental scrapie sources and not enough sheep were included to assess the effect of the PrP genotype on the IHC characteristics. Subsequently studies have indicated that there is an association between PRNP genotype and IHC patterns ${ }^{61-63)}$. It has been proposed that, at least under natural conditions, sheep may be exposed to various strains and specific PRNP genotypes may allow certain strains to propagate preferentially. In addition, the phenotype of a single strain may be influenced by the PrP background ${ }^{61)}$. Therefore, it is believed that because of this interplay between classical scrapie strains and PRNP genotype it is not possible, at least in naturally occurring cases, to accurately discriminate classical scrapie strains by analysing the phenotype of individual sheep. The existence of classical scrapie strains has been established based on the different phenotypes that can emerge from different sources after bioassay in wild type rodents or transgenic mice which express or overexpress a farm animal $P R N P$ transgene whilst murine $P R N P$ has been ablated.

In classical scrapie the agent is also distributed outside the nervous system, mainly in the lymphoreticular tissues where it is readily diagnosed using IHC, Western blot or other related techniques but it does not cause any histological lesions and is considered that it does not interfere with the function of the lymphoreticular system (LRS) ${ }^{64)}$.

\section{Atypical Scrapie}

Until a report in 2003, only classical scrapie cases had been reported in small ruminants ${ }^{65)}$. That report described five cases of ovine TSEs that were distinct from any classical scrapie case known at the time. There were differences in the distribution and intensity of vacuolation, the distribution and the different types of $\mathrm{PrP}^{\mathrm{Sc}}$ deposits identified by IHC, and a strikingly different Western blot profile that included four bands instead of the three bands that are usually associated with animal TSEs. This new phenotype was designated Nor98 and mouse bioassays showed that it transmits only to transgenic mice and produces a phenotype that is distinct from any classical scrapie phenotype identified in these mice ${ }^{36,37)}$. This novel disease attracted a lot of interest as it raised serious questions regarding our knowledge of TSEs and our ability to detect them reliably, as retrospective studies showed that atypical scrapie cases preexisted but they had not been diagnosed as the tests used at the time were not optimised for detecting this disease ${ }^{66,67)}$. Subsequently atypical scrapie was studied extensively and the phenotype of the disease in the original host ${ }^{31,68,69)}$ and in transgenic mice ${ }^{36,37)}$ was described in detail. Knowledge of the distribution of the agent in the nervous system in these cases led to the suggestion that during diagnostic sampling the cerebellum should be collected in addition to the obex. This simple modification has increased significantly the sensitivity of detection of atypical scrapie during surveillance schemes. Unlike classical scrapie, in atypical scrapie the agent is not distributed in peripheral tissues systematically which, in conjunction with its limited distribution in the obex and widespread distribution in the cerebral and cerebellar cortex, have led to the belief that this TSE occurs sporadically ${ }^{70,71)}$. This is supported by epidemiological data indicating that it is not infectious under natural conditions ${ }^{72}$, although it can be transmitted experimentally via the oral route ${ }^{71)}$.

\section{BSE in Small Ruminants}

BSE in cattle was first discovered in the UK in 1985. The diagnosis of the disease was initially based on the identification of spongiform changes in the brain ${ }^{73)}$. At that time no 
other TSE was known in cattle and studies to define the disease phenotype in this species were initiated. One of the most important parameters was to characterise the strain of the agent by defining the disease phenotype in mice that had been challenged with bovine BSE cases $^{74}$. This was subsequently crucial information for demonstrating that BSE was associated with the variant CJD cases that were identified in 1996, as the phenotype of the two diseases in mice was indistinguishable, implying that they were caused by the same strain ${ }^{75-77)}$.

The BSE epidemic was attributed to meat and bone meal supplementation of proprietary cattle feed ${ }^{78}$. As small ruminants were fed the same contaminated food supplements it was rational to assume that BSE might also affect sheep and goats, and subsequent experimental challenges proved this to be the case. Studies were initiated to identify the phenotype of BSE in small ruminants and develop tools that allow its detection and differentiation from scrapie in the field ${ }^{79}$. This EU wide effort has resulted in the identification of naturallyoccurring BSE in two goats ${ }^{80-82)}$.

Although it appears that the PRNP genotype is related to susceptibility, the phenotype of the BSE in affected sheep seems to be uniform, and genotype independent ${ }^{83-85}$. Some disease characteristics, such as clinical signs, are indistinguishable between classical scrapie and $\mathrm{BSE}^{86)}$. Similarly, vacuolation cannot be used differentiate between these two TSEs unless LP are employed ${ }^{43}$ - an impractical solution, as mentioned earlier. $\mathrm{PrP}^{\mathrm{Sc}}$ profiles or distribution patterns on their own also did not offer a reliable means for discrimination for field cases as only a small part of the brain is sampled during surveillance projects. Partially the problem is the wide phenotypical variance within classical scrapie which makes it very difficult to know when you have compiled an exhaustive library of phenotypes, especially given the often limited material available from field cases.

Western blot of tissues from small ruminants affected with BSE after experimental challenge showed that the $\mathrm{PrP}^{\mathrm{Sc}}$ retained the BSE characteristics observed in cattle, i.e. a lower molecular weight unglycosylated band compared to classical scrapie and a different glycoprofile ratio ${ }^{87}$ ). It must be noted that Western blot is the least host-affected parameter during interspecies transmissions and therefore it is generally accepted that if the Western blot properties are retained then the same agent has overcome the transmission barrier and has propagated true in the new recipient. Consequently, changes in the Western blot properties indicate fundamental changes in the strain characteristics of the agent.

In addition to the Western blot two other methods that would allow discrimination between the two TSE entities in small ruminants were developed, discriminatory Western blot and discriminatory IHC. They are both based on the same principle that scrapie and BSE prions are cleaved at different sites during normal in vivo processing producing a core fragment that it is longer in scrapie compared to BSE. Therefore antibodies can be used to exploit that difference. One antibody binds to the C-terminus fragment that is retained to both prions, producing a signal in both classical scrapie and classical BSE; the other binds to the N-terminus fragment that is preserved only in scrapie producing a signal that is detectable in classical scrapie but is lost in BSE. This principle can be applied to Western blot ${ }^{88)}$, PET-blot ${ }^{89)}$ and $\mathrm{IHC}^{85)}$ using either nervous, LRS or any other tissue that may become available during the course of a surveillance programme.

\section{L-type BSE}

As with BSE, the identification of L-type BSE in cattle raised the issue of what the diagnostic criteria would be in small ruminants if they are susceptible, and experimental transmission studies were designed to characterise the phenotype of the disease in sheep ${ }^{90-92}$.

An association between susceptibility and a genotype has been noticed, which is the same as for classical BSE. However, in the susceptible genotypes, the disease phenotype is stable, but none of the contributing characteristics (clinical signs, LP, WB or IHC) resemble any previously known TSE in this species and does not appear to be influenced by $\operatorname{PrP}$ sequence $^{92)}$. Mouse bioassays also support this view, and indicate that the strain characteristics of L-BSE have been retained on cross-species transmission.

Interestingly, in discriminatory Western blot L-BSE appears as scrapie-like as it retains N-terminal antibody signal whilst in D-IHC it is clearly identified as BSE-like.

The main clinical presentation of L-BSE affected sheep is cataplexy, a syndrome that is not normally associated with TSE. Therefore, it is likely that these sheep would not be identified as TSE suspects through passive surveillance.

However, current rapid tests will detect L-BSE cases in all genotypes providing reassurance that they can be identified through active surveillance schemes.

\section{H-type BSE}

As with L-type BSE the emergence of H-type BSE in cattle questioned our capacity to identify this disease in small ruminants if it occurs. To characterise the disease in sheep, experimental transmissions were undertaken, and revealed that sheep are not completely resistant to this TSE although no clinical signs were identified prior to culling five years post inoculation. A limited amount of $\mathrm{PrP}^{\mathrm{Sc}}$ was identified in a small number of challenged sheep, and revealed two 
different patterns. One had only florid aggregates and no diffuse $\mathrm{PrP}^{\mathrm{Sc}}$; the other had diffuse $\mathrm{PrP}^{\mathrm{Sc}}$ deposits in addition to the aggregates. It is not clear if the different presentations correspond to two different phenotypes or if the second presentation reflects a more advanced disease stage. None of these cases showed LRS involvement (own unpublished data).

\section{Conclusions}

Pathology initially offered the only means of diagnosing TSEs and still plays an important role in disease confirmation and strain typing. Although new methods are emerging for TSE diagnosis and some of these may be incorporated in the list of characteristics that are necessary to define TSE strains pathology will continue to play a vital role in identifying and characterizing TSEs either in the original host or in experimental rodents.

\section{Acknowledgements}

The authors would like to thank all current and previous staff members of the Pathology Department for their contributions.

\section{References}

1. Majno G, Joris I. Cells, Tissues, and Disease: Principles of General Pathology. 2 ed. New York, USA: Oxford University Press; 2004.

2. Kumar V, Abbas AK, J.C. A. Robbins \& Cotran Pathologic Basis of Disease. 9 ed. Philadelphia, USA: Elsevier Saunders; 2015.

3. Hadlow WJ. Reflections on the transmissible spongiform encephalopathies. Vet Pathol. 1999; 36: 523-529. [Medline]

4. Gibbons RA, Hunter GD. Nature of the scrapie agent. Nature. 1967; 215: 1041-1043. [Medline]

5. Griffith JS. Self-replication and scrapie. Nature. 1967; 215: 1043-1044. [Medline]

6. Prusiner SB. Novel proteinaceous infectious particles cause scrapie. Science. 1982; 216: 136-144. [Medline]

7. Prusiner SB. Prions. Procceedings of the National Academy of Sciences of the United States of America. 1998; 95: $13363-$ 13383. [Medline]

8. Riek R, Hornemann S, Wider G, Billeter M, Glockshuber R, Wüthrich K. NMR structure of the mouse prion protein domain PrP(121-231). Nature. 1996; 382: 180-182. [Medline]

9. Hornemann S, Schorn C, Wüthrich K. NMR structure of the bovine prion protein isolated from healthy calf brains. $E M B O$ Rep. 2004; 5: 1159-1164. [Medline]

10. Wille H, Michelitsch MD, Guenebaut V, et al. Structural studies of the scrapie prion protein by electron crystallography. Proc Natl Acad Sci U S A. 2002; 99: 3563-3568. [Medline]
11. Govaerts C, Wille H, Prusiner SB, Cohen FE. Evidence for assembly of prions with left-handed beta-helices into trimers. Proc Natl Acad Sci U S A. 2004; 101: 8342-8347. [Medline]

12. Safar J, Wille H, Itri V, et al. Eight prion strains have $\operatorname{PrP}(\mathrm{Sc})$ molecules with different conformations. Nat Med. 1998; 4: 1157-1165. [Medline]

13. Thackray AM, Hopkins L, Klein MA, Bujdoso R. Mouseadapted ovine scrapie prion strains are characterized by different conformers of PrPSc. J Virol. 2007; 81: 12119-12127. [Medline]

14. McKinley MP, Bolton DC, Prusiner SB. A protease-resistant protein is a structural component of the scrapie prion. Cell. 1983; 35: 57-62. [Medline]

15. Prusiner SB, Groth DF, Bolton DC, Kent SB, Hood LE. Purification and structural studies of a major scrapie prion protein. Cell. 1984; 38: 127-134. [Medline]

16. Stack MJ. Western immunobloting techniques for the study of transmissible spongiform encephalopathies. In: Lehmann $\mathrm{S}$, Grassi J, editors. Techniques in prion research. Bsael, Switzerland: Birkhauser; 2004.

17. Stahl N, Baldwin MA, Teplow DB, et al. Structural studies of the scrapie prion protein using mass spectrometry and amino acid sequencing. Biochemistry (Mosc). 1993; 32: 1991-2002. [Medline]

18. Prusiner SB. Shattuck lecture-neurodegenerative diseases and prions. N Engl J Med. 2001; 344: 1516-1526. [Medline]

19. Regulation (ec) no $999 / 2001$ of the european parliament and of the council of 22 May 2001 laying down rules for the prevention, control and eradication of certain transmissible spongiform encephalopathies. Official Journal of the European Union. 2001.

20. Simmons MM, Stack M, Konold T, Webster K. Bovine spongiform encephalopathy. In: Commision OBS, editor. OIE Manual of Diagnostic Tets and Vaccines for Terestrial Animals. 1.7 ed. Paris, France: OIE; 2012. p. 662-673.

21. Simmons MM, Stack M, Konold T, Matthews D. Scrapie. In: Commision OBS, editor. OIE Manual of Diagnostic Tests and Vaccines fro Terestrial Animals. 2. 7 ed. Paris, France: OIE; 2012. p. 1045-1054.

22. Wells GA, Wilesmith JW, McGill IS. Bovine spongiform encephalopathy: a neuropathological perspective. Brain Pathol. 1991; 1: 69-78. [Medline]

23. Wells GA, Spencer YI, Haritani M. Configurations and topographic distribution of $\mathrm{PrP}$ in the central nervous system in bovine spongiform encephalopathy: an immunohistochemical study. 1994. p. 350-352.

24. van Keulen LJM, Schreuder BE, Meloen RH, et al. Immunohistochemical detection and localization of prion protein in brain tissue of sheep with natural scrapie. Vet Pathol. 1995; 32: 299-308. [Medline]

25. Ryder SJ, Spencer YI, Bellerby PJ, March SA. Immunohistochemical detection of PrP in the medulla oblongata of sheep: the spectrum of staining in normal and scrapie-affected sheep. Vet Rec. 2001; 148: 7-13. [Medline]

26. Haritani M, Spencer YI, Wells GA. Hydrated autoclave pretreatment enhancement of prion protein immunoreactivity in formalin-fixed bovine spongiform encephalopathy-affected brain. Acta Neurol (Napoli). 1994; 87: 86-90. [Medline] 
27. Bell JE, Gentleman SM, Ironside JW, et al. Prion protein immunocytochemistry-UK five centre consensus report. Neuropathol Appl Neurobiol. 1997; 23: 26-35. [Medline]

28. Bencsik A, Baron T. Bovine spongiform encephalopathy agent in a prion protein (PrP)ARR/ARR genotype sheep after peripheral challenge: complete immunohistochemical analysis of disease-associated $\operatorname{PrP}$ and transmission studies to ovine-transgenic mice. J Infect Dis. 2007; 195: 989-996. [Medline]

29. Fraser $\mathrm{H}$. The pathology of natural and experimental scrapie. In: Kimberlin RH, editor. Slow virus diseases of animals and man. Frontiers in biology. 44. Amsterdam-Oxford: NorthHolland Publishing Company; 1976. p. 267-305.

30. Bruce ME, Fraser H, McBride PA, Scott JR, Dickinson AG. The basis of strain variation in scrapie. In: Prusiner SB, Collinge J, Powell J, Anderton B, editors. Prion Diseases of Humans and Animals. Chichester: Ellis Horwood; 1992. p. 497-508.

31. Simmons MM, Konold T, Simmons HA, et al. Experimental transmission of atypical scrapie to sheep. BMC Vet Res. 2007; 3: 20. [Medline]

32. Thackray AM, Hopkins L, Lockey R, Spiropoulos J, Bujdoso R. Emergence of multiple prion strains from single isolates of ovine scrapie. J Gen Virol. 2011; 92: 1482-1491. [Medline]

33. Beck KE, Vickery CM, Lockey R, et al. The interpretation of disease phenotypes to identify TSE strains following murine bioassay: characterisation of classical scrapie. Vet Res. 2012; 43: 77. [Medline]

34. Dickinson AG, Meikle VMH, Fraser H. Identification of a gene which controls the incubation period of some strains of scrapie agent in mice. J Comp Pathol. 1968; 78: 293-299. [Medline]

35. Fraser H, Dickinson AG. Scrapie in mice. Agent-strain differences in the distribution and intensity of grey matter vacuolation. J Comp Pathol. 1973; 83: 29-40. [Medline]

36. Le Dur A, Béringue V, Andréoletti O, et al. A newly identified type of scrapie agent can naturally infect sheep with resistant PrP genotypes. Proc Natl Acad Sci U S A. 2005; 102: 16031-16036. [Medline]

37. Griffiths PC, Spiropoulos J, Lockey R, et al. Characterization of atypical scrapie cases from Great Britain in transgenic ovine PrP mice. J Gen Virol. 2010; 91: 2132-2138. [Medline]

38. Corda E, Beck KE, Sallis RE, et al. The interpretation of disease phenotypes to identify TSE strains in mice: characterisation of BSE using PrPSc distribution patterns in the brain. Vet Res. 2012; 43: 86. [Medline]

39. Dickinson AG, Meikle VM. Host-genotype and agent effects in scrapie incubation: change in allelic interaction with different strains of agent. Mol Genet Genomics. 1971; 112: 73-79. [Medline]

40. Westaway D, Goodman PA, Mirenda CA, McKinley MP, Carlson GA, Prusiner SB. Distinct prion proteins in short and long scrapie incubation period mice. Cell. 1987; 51: 651-662. [Medline]

41. Manolakou K, Beaton J, McConnell I, et al. Genetic and environmental factors modify bovine spongiform encephalopathy incubation period in mice. Procceedings of the National Academy of Sciences of the United States of America. 2001; 98: 7402-7407. [Medline]
42. Fraser H, Dickinson AG. The sequential development of the brain lesion of scrapie in three strains of mice. J Comp Pathol. 1968; 78: 301-311. [Medline]

43. Ligios C, Jeffrey M, Ryder SJ, Bellworthy SJ, Simmons MM. Distinction of scrapie phenotypes in sheep by lesion profiling. J Comp Pathol. 2002; 127: 45-57. [Medline]

44. Bruce ME. TSE strain variation. Br Med Bull. 2003; 66: 99108. [Medline]

45. Beck KE, Chaplin M, Stack M, et al. Lesion profiling at primary isolation in RIII mice is insufficient in distinguishing BSE from classical scrapie. Brain Pathol. 2010; 20: 313-322. [Medline]

46. Beck KE, Sallis RE, Lockey R, et al. Use of murine bioassay to resolve ovine transmissible spongiform encephalopathy cases showing a bovine spongiform encephalopathy molecular profile. Brain Pathol. 2012; 22: 265-279. [Medline]

47. González L, Martin S, Begara-McGorum I, et al. Effects of agent strain and host genotype on PrP accumulation in the brain of sheep naturally and experimentally affected with scrapie. J Comp Pathol. 2002; 126: 17-29. [Medline]

48. Sisó S, González L, Houston F, Hunter N, Martin S, Jeffrey $\mathrm{M}$. The neuropathologic phenotype of experimental ovine BSE is maintained after blood transfusion. Blood. 2006; 108: 745-748. [Medline]

49. Sisó S, Jeffrey M, Martin S, Chianini F, Dagleish MP, González L. Characterization of strains of ovine transmissible spongiform encephalopathy with a short PrPd profiling method. J Comp Pathol. 2010; 142: 300-310. [Medline]

50. Beck KE, Sallis RE, Lockey R, Simmons MM, Spiropoulos J. Ovine PrP genotype is linked with lesion profile and immunohistochemistry patterns after primary transmission of classical scrapie to wild-type mice. J Neuropathol Exp Neurol. 2010; 69: 483-497. [Medline]

51. van Keulen LJ, Langeveld JP, Dolstra CH, et al. TSE strain differentiation in mice by immunohistochemical PrP profiles and triplex Western blot. Neuropathol Appl Neurobiol. 2015; 41: 756-779. [Medline]

52. Hecker R, Taraboulos A, Scott M, et al. Replication of distinct scrapie prion isolates is region specific in brains of transgenic mice and hamsters. Genes Dev. 1992; 6: 1213-1228. [Medline]

53. Taraboulos A, Jendroska K, Serban D, Yang SL, DeArmond SJ, Prusiner SB. Regional mapping of prion proteins in brain. Proc Natl Acad Sci U S A. 1992; 89: 7620-7624. [Medline]

54. Kimura KM, Yokoyama T, Haritani M, et al. In situ detection of cellular and abnormal isoforms of prion protein in brains of cattle with bovine spongiform encephalopathy and sheep with scrapie by use of a histoblot technique. J Vet Diagn Invest. 2002; 14: 255-257. [Medline]

55. Schulz-Schaeffer WJ, Tschöke S, Kranefuss N, et al. The paraffin-embedded tissue blot detects $\operatorname{PrP}(\mathrm{Sc})$ early in the incubation time in prion diseases. Am J Pathol. 2000; 156: 51-56. [Medline]

56. Ritchie DL, Head MW, Ironside JW. Advances in the detection of prion protein in peripheral tissues of variant Creutzfeldt-Jakob disease patients using paraffin-embedded tissue blotting. Neuropathol Appl Neurobiol. 2004; 30: 360368. [Medline] 
57. Brown P, Bradley R. 1755 and all that: a historical primer of transmissible spongiform encephalopathy. Br Med J. 1998; 317: 1688-1692. [Medline]

58. McGowan JP. Scrapie in sheep. The Scottisch journal of agriculture. 1922;5:365-375.

59. Hunter N, Foster JD, Dickinson AG, Hope J. Linkage of the gene for the scrapie-associated fibril protein $(\operatorname{PrP})$ to the Sip gene in Cheviot sheep. Vet Rec. 1989; 124: 364-366. [Medline]

60. Ersdal C, Ulvund MJ, Espenes A, Benestad SL, Sarradin P, Landsverk T. Mapping PrPSc propagation in experimental and natural scrapie in sheep with different PrP genotypes. Vet Pathol. 2005; 42: 258-274. [Medline]

61. Spiropoulos J, Casalone C, Caramelli M, Simmons MM. Immunohistochemistry for PrPSc in natural scrapie reveals patterns which are associated with the PrP genotype. Neuropathol Appl Neurobiol. 2007; 33: 398-409. [Medline]

62. Sisó S, Chianini F, Eaton SL, et al. Disease phenotype in sheep after infection with cloned murine scrapie strains. Prion. 2012; 6: 174-183. [Medline]

63. González L, Pitarch JL, Martin S, et al. Influence of polymorphisms in the prion protein gene on the pathogenesis and neuropathological phenotype of sheep scrapie after oral infection. J Comp Pathol. 2014; 150: 57-70. [Medline]

64. van Keulen LJM, Schreuder BE, Vromans ME, Langeveld JP, Smits MA. Pathogenesis of natural scrapie in sheep. 2000. p. 57-71.

65. Benestad SL, Sarradin P, Thu B, Schönheit J, Tranulis MA, Bratberg B. Cases of scrapie with unusual features in Norway and designation of a new type, Nor98. Vet Rec. 2003; 153: 202-208. [Medline]

66. Webb PR, Powell L, Denyer M, et al. A retrospective immunohistochemical study reveals atypical scrapie has existed in the United Kingdom since at least 1987. J Vet Diagn Invest. 2009; 21: 826-829. [Medline]

67. Bruce ME, Nonno R, Foster J, et al. Nor98-like sheep scrapie in the United Kingdom in 1989. Vet Rec. 2007; 160: 665-666. [Medline]

68. Moore SJ, Simmons M, Chaplin M, Spiropoulos J. Neuroanatomical distribution of abnormal prion protein in naturally occurring atypical scrapie cases in Great Britain. Acta Neuropathol (Berl). 2008; 116: 547-559. [Medline]

69. Simmons MM, Konold T, Thurston L, Bellworthy SJ, Chaplin MJ, Moore SJ. The natural atypical scrapie phenotype is preserved on experimental transmission and sub-passage in PRNP homologous sheep. BMC Vet Res. 2010; 6: 14. [Medline]

70. Andréoletti O, Orge L, Benestad SL, et al. Atypical/Nor98 scrapie infectivity in sheep peripheral tissues. PLoS Pathog. 2011; 7: e1001285. [Medline]

71. Simmons MM, Moore SJ, Konold T, et al. Experimental oral transmission of atypical scrapie to sheep. Emerg Infect Dis. 2011; 17: 848-854. [Medline]

72. Fediaevsky A, Maurella C, Nöremark M, et al. The prevalence of atypical scrapie in sheep from positive flocks is not higher than in the general sheep population in 11 European countries. BMC Vet Res. 2010; 6: 9. [Medline]
73. Wells GA, Scott AC, Johnson CT, et al. A novel progressive spongiform encephalopathy in cattle. Vet Rec. 1987; 121: 419-420. [Medline]

74. Fraser H, Bruce ME, Chree A, McConnell I, Wells GAH. Transmission of bovine spongiform encephalopathy and scrapie to mice. J Gen Virol. 1992; 73: 1891-1897. [Medline]

75. Hill AF, Desbruslais M, Joiner S, et al. The same prion strain causes vCJD and BSE. Nature. 1997; 389: 448-450, 526. [Medline]

76. Bruce ME, Will RG, Ironside JW, et al. Transmissions to mice indicate that 'new variant' CJD is caused by the BSE agent. Nature. 1997; 389: 498-501. [Medline]

77. Scott MR, Will R, Ironside J, et al. Compelling transgenetic evidence for transmission of bovine spongiform encephalopathy prions to humans. Proc Natl Acad Sci U S A. 1999; 96: 15137-15142. [Medline]

78. Wilesmith JW, Wells GA, Cranwell MP, Ryan JB. Bovine spongiform encephalopathy: epidemiological studies. Vet Rec. 1988; 123: 638-644. [Medline]

79. Regulation C. (EC) No 36/2005 of 12 January 2005 amending Annexes III and X to Regulation (EC) No 999/2001 of the European Parliament and of the Council as regards epidemiosurveillance for transmissible spongiform encephalopathies in bovine, ovine and caprine animals. Official Journal of the European Union. 2005.

80. Eloit M, Adjou K, Coulpier M, et al. BSE agent signatures in a goat. Vet Rec. 2005; 156: 523-524. [Medline]

81. Jeffrey M, Martin S, González L, et al. Immunohistochemical features of $\operatorname{Pr} \mathrm{P}(\mathrm{d})$ accumulation in natural and experimental goat transmissible spongiform encephalopathies. J Comp Pathol. 2006; 134: 171-181. [Medline]

82. Spiropoulos J, Lockey R, Sallis RE, et al. Isolation of prion with BSE properties from farmed goat. Emerg Infect Dis. 2011; 17: 2253-2261. [Medline]

83. Foster JD, Hope J, Fraser H. Transmission of bovine spongiform encephalopathy to sheep and goats. Vet Rec. 1993; 133: 339-341. [Medline]

84. Jeffrey M, Ryder S, Martin S, et al. Oral inoculation of sheep with the agent of bovine spongiform encephalopathy (BSE). 1. Onset and distribution of disease-specific PrP accumulation in brain and viscera. J Comp Pathol. 2001; 124: 280-289. [Medline]

85. Jeffrey M, Martin S, González L, Ryder SJ, Bellworthy SJ, Jackman R. Differential diagnosis of infections with the bovine spongiform encephalopathy (BSE) and scrapie agents in sheep. J Comp Pathol. 2001; 125: 271-284. [Medline]

86. Konold T, Bone G, Vidal-Diez A, et al. Pruritus is a common feature in sheep infected with the BSE agent. BMC Vet Res. 2008; 4: 16. [Medline]

87. Thuring CM, Erkens JH, Jacobs JG, et al. Discrimination between scrapie and bovine spongiform encephalopathy in sheep by molecular size, immunoreactivity, and glycoprofile of prion protein. J Clin Microbiol. 2004; 42: 972-980. [Medline] 
88. Stack MJ, Chaplin MJ, Clark J. Differentiation of prion protein glycoforms from naturally occurring sheep scrapie, sheep-passaged scrapie strains (CH1641 and SSBP1), bovine spongiform encephalopathy (BSE) cases and Romney and Cheviot breed sheep experimentally inoculated with BSE using two monoclonal antibodies. Acta Neuropathol (Berl). 2002; 104: 279-286. [Medline]

89. Webb PR, Denyer M, Gough J, Spiropoulos J, Simmons MM, Spencer YI. Paraffin-embedded tissue blot as a sensitive method for discrimination between classical scrapie and experimental bovine spongiform encephalopathy in sheep. $J$ Vet Diagn Invest. 2011; 23: 492-498. [Medline]
90. Matsuura Y, Iwamaru Y, Masujin K, et al. Distribution of abnormal prion protein in a sheep affected with L-type bovine spongiform encephalopathy. J Comp Pathol. 2013; 149: 113-118. [Medline]

91. Nicot S, Bencsik A, Migliore S, et al. L-type bovine spongiform encephalopathy in genetically susceptible and resistant sheep: changes in prion strain or phenotypic plasticity of the disease-associated prion protein? J Infect Dis. 2014; 209: 950-959. [Medline]

92. Simmons MM, Chaplin MJ, Konold T, et al. L-BSE experimentally transmitted to sheep presents as a unique disease phenotype. Vet Res. 2016; 47: 112. [Medline] 